\title{
INDUCTION OF NUCLEAR DECONDENSATION OF MAMMALIAN SPERMATOZOA IN VITRO
}

\author{
CHERRIE A. MAHI AND RYUZO YANAGIMACHI \\ Department of Anatomy and Reproductive Biology, \\ University of Hawaii School of Medicine, \\ Honolulu, Hawaii 96822, U.S.A.
}

\section{(Received 10th December 1974)}

The nucleus of the mammalian spermatozoon is an exceptionally stable organelle requiring very rigorous chemical treatments to free its chromatin (Borenfreund et al., 1961). In spite of this, the nucleus swells and its chromatin begins to decondense very rapidly as the spermatozoon is incorporated into the egg cytoplasm (Austin, 1961; Yanagimachi \& Noda, 1970; Bedford, 1972). As yet, the mechanism underlying this phenomenon has not been directly examined.

Various methods have been used to decondense sperm nuclei and to isolate and characterize the sperm chromatin and nuclear proteins (Borenfreund $e t a l$., 1961; Henricks \& Mayer, 1965; Lung, 1972). Sodium dodecyl sulphate (SDS, an anionic surfactant) and dithiothreitol (DTT, a reagent which specifically cleaves disulphide linkages) have been used to study nuclear stabilization during maturation of mammalian spermatozoa (Calvin \& Bedford, 1971; Calvin et al., 1973). Nuclear stabilization by disulphide (-S-S-) bonding has been studied from an evolutionary standpoint by Bedford \& Calvin (1974), who have found that this -S-S- bonding is prominent in the spermatozoa only of eutherian mammals. In the present study, the types of chemicals that can decondense mammalian sperm nuclei were determined, then the common characteristics of these chemicals were evaluated so that possible inferences could be made about the mechanism of nuclear decondensation during fertilization.

Epididymal spermatozoa of the golden hamster, rat, guinea-pig and rabbit were obtained by puncturing the excised cauda epididymidis with a needle and squeezing the spermatozoa into a Petri dish containing $0.9 \% \mathrm{NaCl}$ at $37^{\circ} \mathrm{C}$. Pellets of frozen canine semen were prepared according to the techniques of Seager (1969) and were air-shipped from Oregon to Hawaii in liquid nitrogen $\left(-196^{\circ} \mathrm{C}\right)$. For these experiments, pellets were thawed rapidly in $0.9 \% \mathrm{NaCl}$ $\left(37^{\circ} \mathrm{C}\right)$, and fresh canine ejaculates were obtained for comparison. Both fresh and frozen-thawed semen were washed by centrifugation two or four times in $0.9 \% \mathrm{NaCl}$ and resuspended in $0.9 \% \mathrm{NaCl}$. The sperm suspension of each species $(0.1 \mathrm{ml})$ was mixed with an equal volume of a test solution in a $5-\mathrm{ml}$ glass test-tube. The final concentration of spermatozoa varied from $10^{5}$ to $10^{7}$ spermatozoa $/ \mathrm{ml}$. The tubes were sealed with Parafilm (American Can Co., Neenah, Wisconsin) and incubated at $37^{\circ} \mathrm{C}$. At the end of incubation, the $\mathrm{pH}$ was measured and the degree of nuclear decondensation was determined by 
examining the suspension with a phase-contrast microscope at $\times 400$ magnification.

Most reagents were first tested at final concentrations of $1 \mathrm{~m}$ in either distilled water or $0.5 \%$ SDS, but higher concentrations of inorganic acids, $\mathrm{KCN}$ and $\mathrm{NH}_{4} \mathrm{OH}$ were tested. Thioglycolic acid was neutralized with $1 \mathrm{M}-\mathrm{NaOH}$ to $\mathrm{pH} 9 \cdot 0$. Enzymes (including proteases, nucleases and many others) were dissolved to a concentration of $1 \%$ in $0.2 \mathrm{M}$-phosphate buffer at the $\mathrm{pH}$ of optimum activity for each enzyme. Before these enzyme tests, the spermatozoa were sonicated for $5 \mathrm{~min}$ in distilled water at $20 \mathrm{KHz}$ to disrupt the sperm membranes. Each reagent was tested first by incubation with hamster spermatozoa for as long as $3 \mathrm{hr}$ before it was ruled effective or ineffective. The tests were then standardized by determining the optimum concentrations of the effective reagents, i.e. after incubation for $30 \mathrm{~min}$ the nuclear decondensation was readily apparent (Pl. 1, Figs 1 to 4 ), but the nuclei were not completely dispersed. Reagents that were effective in decondensing hamster sperm nuclei were tested on the spermatozoa of the other species.

Table 1. Reagents effective in decondensing sperm nuclei of five different mammalian species

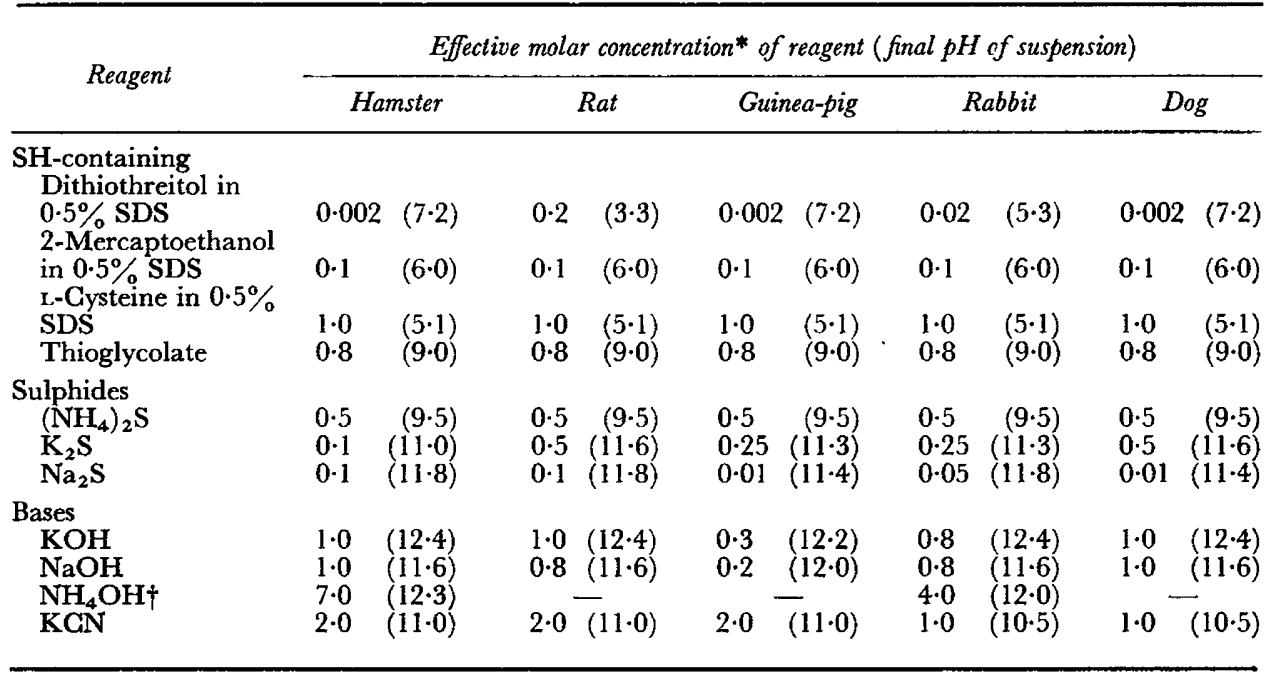

* Effective concentration is that concentration which produces readily recognizable nuclear decondensation in $30 \mathrm{~min}$ (see Pl. 1, Figs 1 to 4).

$\dagger \mathrm{NH}_{4} \mathrm{OH}$ (4 to $\left.7 \mathrm{M}, \mathrm{pH} 12\right)$ produced only slight swelling of hamster and rabbit spermatozoa and none in the other species.

Of approximately 200 chemicals tested, only the eleven in Table 1 produced visible nuclear decondensation of hamster spermatozoa and all of these, except $\mathrm{NH}_{4} \mathrm{OH}$, were also effective in decondensing the spermatozoa of the other species. Dithiothreitol, cysteine and 2-mercaptoethanol were effective only in the presence of SDS. As can be seen from Table 1, there were species differences in the resistance of the nuclei to some reagents, rat spermatozoa being the most resistant and guinea-pig spermatozoa the least resistant. Rabbit spermatozoa 


\section{PLATE 1}

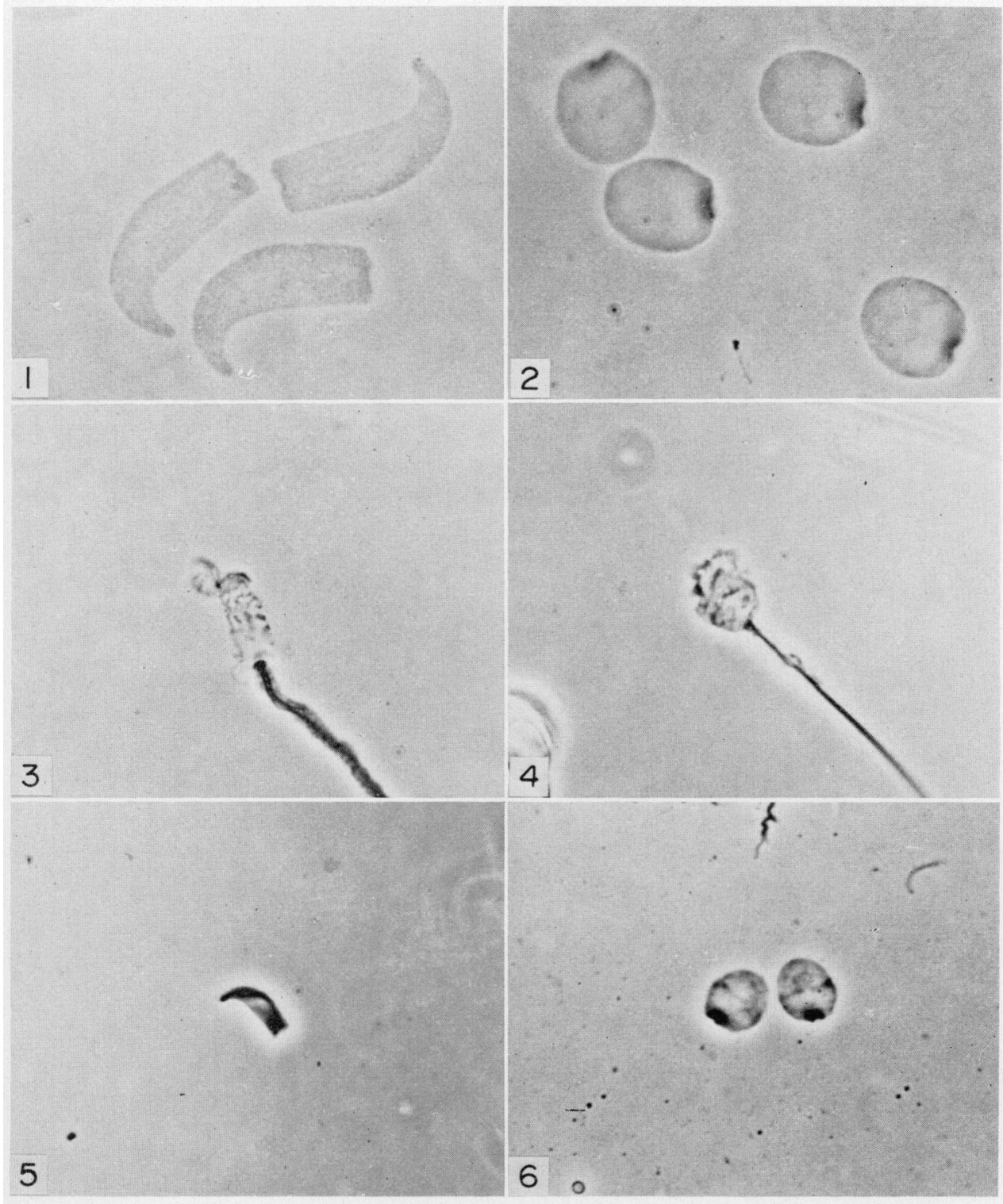

FIGs 1 and 2. Golden hamster (Fig. 1) and guinea-pig (Fig. 2) spermatozoa incubated for $30 \mathrm{~min}$ in $0.002 \mathrm{M}$-dithiothreitol with $0.5 \%$ SDS. $\times 1000$.

Figs 3 and 4. Golden hamster (Fig. 3) and guinea-pig (Fig. 4) spermatozoa incubated for $30 \mathrm{~min}$ in $\mathbf{0 . 8} \mathrm{m}$-thioglycolate, $\mathrm{pH} 9 \cdot 0 . \times 1000$.

FIGs 5 and 6. Golden hamster (Fig. 5) and guinea-pig (Fig. 6) spermatozoa sonicated for $5 \mathrm{~min}$ in distilled water at $20 \mathrm{KHz}$ and left in distilled water for $24 \mathrm{hr} . \times 1000$.

(Facing p. 294) 
were rather resistant to DTT unless the concentration of SDS was doubled. All but the first four reagents produced solutions with high $\mathrm{pH}$ values. The effectiveness of these reagents could not be directly attributed to $\mathrm{pH}$, however, since $7 \mathrm{M}-\mathrm{NH}_{4} \mathrm{OH}, \mathrm{pH} 12 \cdot 3$, produced an effect in only two of the five species and this was slight. Unlike strong bases, strong acids $\left(\mathrm{HCl}, \mathrm{H}_{2} \mathrm{SO}_{4}\right)$ failed to decondense the sperm nuclei even at concentrations of 5 and $2.5 \mathrm{~m}$ respectively. Other ineffective reagents included reduced glutathione (GSH), proteases, DNAase, $\mathrm{CaS}, \mathrm{H}_{2} \mathrm{~S}$, distilled water, and detergents such as Triton X-100 and SDS alone. Sonication for $5 \mathrm{~min}$ in distilled water at $20 \mathrm{KHz}$ destroyed the extranuclear portions of the spermatozoa but left the nuclei intact. Soaking the spermatozoa in distilled water for $24 \mathrm{hr}$ after sonication did not alter the appearance of the nuclei (Pl. 1, Figs 5 and 6).

In most cases, the sperm nuclei swelled uniformly (PI. 1, Figs 1 and 2), but in thioglycolate (Pl. 1, Figs 3 and 4$)$ and $\left(\mathrm{NH}_{4}\right)_{2} \mathrm{~S}$, the chromatin first became granular then escaped from the nucleus.

When frozen-thawed and fresh canine spermatozoa were compared after only two washings, the former were consistently more resistant than the latter to all the reagents. After four washings, however, no differences were detectable. Apparently two washings are not sufficient to remove the cryoprotective agents used in diluting the semen before freezing ( $11 \%$ lactose, $4 \%$ glycerol and $20 \%$ egg yolk; Seager, 1969).

Reagents that cause nuclear decondensation can be divided into three categories. The thiol reagents are active at $\mathrm{pH} 3 \cdot 3$ to $9 \cdot 0$ : they will split intracellular -S-S- linkages, but as decondensing agents, DTT, cysteine and mercaptoethanol require the presence of SDS. The second category, inorganic sulphides, may be active either on account of the sulphide ion or because of the high $\mathrm{pH}$ $(9.5$ to 11.8$)$ of their solutions. Reagents in the third category $(\mathrm{NaOH}, \mathrm{KOH}$, $\mathrm{NH}_{4} \mathrm{OH}$ and $\mathrm{KGN}$ ) have $\mathrm{pH}$ values above 10.5 at effective concentrations. It is possible that reagents in the second and third categories are acting by hydrolysing the nuclear proteins, but $\mathrm{KCN}$ (HCN in solution) is also known to split -S-S- bonds (Jocelyn, 1972).

Of the effective reagents, only cysteine can be considered physiological, but normally there is very little free cysteine in cells compared with the $1 \mathrm{~m}$ concentration required in vitro. On the other hand, GSH, a tripeptide containing cysteine, is the most abundant non-protein thiol in cells (Jocelyn, 1972). In the present study, it did not induce nuclear decondensation, but this could be due to autoxidation of GSH to less reactive oxidized glutathione (GSSG). In cells, glutathione reductase and NADH or NADPH maintain GSH in the reduced form (Jocelyn, 1972), so it is possible that GSH is involved in the rapid decondensation of sperm nuclei following fertilization. Although the cytoplasm of most cells contains considerable quantities of both protein and non-protein thiols (especially GSH), the egg cytoplasm cannot always decondense the sperm nucleus. Yanagimachi \& Usui (1972) have shown that the hamster egg acquires this ability at approximately the time the germinal vesicle begins to break down and loses it again following pronucleus formation. This ability returns just before the first cleavage ( $R$. Yanagimachi and $N$. Usui, unpublished results). In most cells (including sea urchin eggs) there is a cycle in which a 
dramatic fall in the concentration of low molecular weight thiols occurs at the time of condensation of the chromosomes during cell division. The fall is accompanied by a rise in the thiol content of the insoluble proteins of the nucleus. The original levels are restored just before cytokinesis (Jocelyn, 1972). If this chain of events extends into the cytoplasm, it may partly explain the effects of egg maturation on sperm head swelling. Low molecular weight thiols such as GSH might reduce the intra-chain -S-S- linkages of an inactive enzyme, yielding GSSG and an enzyme with active $-\mathrm{SH}$ groups. This enzyme could then reduce the $-\mathrm{S}-\mathrm{S}-\mathrm{b}$ bonds of sperm nuclear proteins.

Species differences recorded in Table 1 may be due to differences in the degree of $-\mathrm{S}-\mathrm{S}$ - bonding in the sperm nuclei or to differences in the resistance of the sperm membranes to the chemicals. The fact that the nuclei of frozenthawed canine spermatozoa were no less resistant than fresh nuclei to the decondensing agents further attests to the safety of freezing semen and storing it for insemination at a later date (Sherman \& Char, 1974).

\section{Note added in proof}

Since this manuscript was submitted, a fresh lot of GSH has been found to decondense hamster sperm nuclei in the presence of SDS.

This study was supported by grants from NIH-USPHS (HD-03402), the Population Council and the Ford Foundation. The authors are grateful to Dr S. W. J. Seager and Mr Carrol Platz for providing pellets of frozen canine semen and to Dr B. J. Rogers for her assistance in the preparation of the manuscript.

\section{REFERENGES}

Austin, G.R. (1961) The Mammalian Egg. Thomas, Springfield, Illinois.

BEDFORD, J.M. (1972) An electron microscopic study of sperm penetration into the rabbit egg after natural mating. Am. F. Anat. 133, 213-254.

BeDFoRd, J.M. \& GALvin, H.I. (1974) The occurrence and possible functional significance of -S-Scrosslinks in sperm heads, with particular reference to eutherian mammals. $\mathcal{F}$. exp. Zool. 188, 137-156.

Borenfreund, E., FitT, E. \& Bendich, A. (1961) Isolation and properties of deoxyribonucleic acid from mammalian sperm. Nature, Lond. 191, 1375-1377.

GALvin, H.I. \& BEDFoRD, J.M. (1971) Formation of disulphide bonds in the nucleus and accessory structures of mammalian spermatozoa during maturation in the epididymis. $\mathcal{F}$. Reprod. Fert., Suppl. 13, 65-75.

Galvin, H.I., YU, C.C. \& Bedpord, J.M. (1973) Effects of epididymal maturation, zinc (II) and copper (II) on the reactive sulfhydryl content of structural elements in rat spermatozoa. Expl Cell Res. 81, 333-341.

HeNRICKs, D.M. \& MAYER, D.T. (1965) Isolation and characterization of a basic keratin-like protein from mammalian spermatozoa. Expl Cell Res. 40, 402-412.

Jocelyn, P.C. (1972) Biochemistry of the SH Group. Academic Press, New York.

LuNG, G. (1972) Ultrastructure and chromatin disaggregation of human sperm head with thioglycolate treatment. 7. Cell Biol. 52, 179-186.

SeAGER, S.W.J. (1969) Successful pregnancies utilizing frozen dog semen. A.I. Digest, 17, 12-13.

Sherman, J.K. \& Char, F. (1974) Stability of Y chromosome fluorescence during freeze-thawing and frozen storage of human spermatozoa. Fert. Steril. 25, 311-314.

YANAGIMACHI, R. \& NoDA, Y.D. (1970) Electron microscope studies of sperm incorporation into the golden hamster egg. Am. F. Anat. 128, 429-462.

Yanagimachi, R. \& Usui, N. (1972) The appearance and disappearance of factors involved in sperm chromatin decondensation in the hamster egg. F. Cell Biol. 55, 293a. 